\title{
REGULASI DIRI SISWA SEKOLAH KHUSUS OLAHRAGA RAGUNAN BINAAN PEMERINTAH PROVINSI DKI JAKARTA
}

\author{
Novendawati Wahyu Sitasari ${ }^{1}$, Wara Rahmawati ${ }^{2}$, Yuli Asmi Rozali ${ }^{3}$ \\ ${ }^{1,3}$ Fakultas Psikologi Universitas Esa Unggul, Jakarta Barat, Indonesia, ${ }^{2}$ Kemenpora,Jakarta, \\ Indonesia \\ novenda@esaunggul.ac.id
}

\begin{abstract}
ABSTRAK
Tujuan dari penelitian ini adalah mengetahui bagaimanakah regulasi diri siswa SKO Ragunan. Populasi dan sampel dari penelitian ini berjumlah 222 siswa SKO Ragunan Binaan Pemprov DKI yang terdiri dari 115 siswa laki-laki dan 107 siswa perempuan. Penelitian ini termasuk ke dalam jenis penelitian kuantitatif yang sifatnya deskriptif. Pengambilan data dilakukan dengan menyebarkan kuesioner regulasi diri berdasar teori Omrod (2009). Analisa data dilakukan dengan membuat kategori skor total regulasi diri. Hasil penelitian diperoleh bahwa siswa SKO Ragunan Binaan Pemprov DKI yang memiliki regulasi sedang 86,5\% lebih banyak dibandingkan yang memililiki regulasi tinggi13,5\%. Selain itu siswa laki-laki lebih memiliki regulasi yang baik dibandingkan siswa perempuan. Dan siswa dengan cabang olahraga beregu atau tim memiliki regulasi yang tinggi dibanding siswa dari cabang olahraga individu.
\end{abstract}

Kata Kunci: Regulasi Diri; Atlet; Siswa Olahraga

\begin{abstract}
The purpose of this study was to find out how self-regulation of SKO Ragunan students. The population and sample from this study amounted to 222 SKO Ragunan Fostered DKI Jakarta Provincial Government consisting of 115 male students and 107 female students. This research belongs to the type of quantitative research that is descriptive in nature. Data is collected by distributing self-regulation questionnaires based on the theory of Omrod (2009). Data analysis is done by making a total score category of self-regulation. The results showed that students of SKO Ragunan Fostered by the DKI Provincial Government who had medium regulation were $86.5 \%$ more than those who had high regulation of $13.5 \%$. Besides male students have more good regulation than female students. And students with team or team sports have higher regulations than students from individual sports
\end{abstract}

Keywords: Self Regulation; Athlete; Sports Students 


\section{PENDAHULUAN}

Olahraga, dewasa ini dijadikan sebagai sebuah profesi bagi sebagian individu. Selain itu adanya dukungan pemerintah yang akan memberikan bonus ketika atlet berhasil menjadi kampiun dalam sebuah kejuaraan turut memberikan semangat dan motivasi tersendiri bagi atlet untuk mampu meraih prestasi (Kusumawati, 2017). Profesi sebagai atlet tidak hanya digeluti oleh individu yang sudah dewasa, namun juga oleh individu yang masih menempuh pendidikan. Siswa yang ingin memasuki sekolah dengan basis kelas khusus olahraga akan melalui tahapan tes diantara tes fisik sesuai dengan kemampuan atlet dan mulai dari sekolah dasar memiliki nilai akademik rata-rata 75 . Hal tersebut merupakan salah satu bentuk Peraturan Menteri Pendidikan Nasional Republik Indonesia nomor 34 tahun 2006 tentang pembinaan prestasi peserta didik yang memiliki potensi kecerdasan atau bakat istimewa.

Adanya peraturan tersebut membuat siswa atlet tetap harus mengikuti jam belajar di sekolah sama seperti siswa lainnya di sekolah. Siswa atlet juga harus mengikuti peraturan yang ada di sekolah seperti memenuh jumlah absensi, jam masuk sekolah, serta mereka juga harus mencapai nilai minimum 75 untuk dapat lulus satu mata pelajaran di kelas. Selain itu siswa juga wajib mengikuti latihan untuk cabang olahraga masing-masing sebelum jam sekolah dimulai dan setelah jam sekolah berakhir. Siswa atlet pun dituntut untuk dapt memenuhi tuntutan akademis seperti terpenuhinya KKM dalam setiap mata pelajaran, serta tugas-tugas sekolah yang harus diselesaikan. Selain tuntutan akademik mereka juga harus bias memenuhi tuntutan sebagai atlet yaitu mengikuti jadwal latihan dan prestasi olahraga sebagai atlet.

Pemenuhan kewajiban sebagai siswa dan atlet seringkali membuat prestasi belajar yang diperoleh siswa mengalami penurunan atau kesulitan untuk memenuhi KKM yang ditentukan. Mengatur waktu menjadi permasalahan utama bagi siswa atlet. Pada saat jam belajar di sekolah, siswa atlet cenderung mengalami kelelahan setelah latihan, sedangkan waktu untuk belajar berkurang karena jadwal latihan yang padat. Tidak banyak dari siswa atlet yang memiliki strategi khusus dalam mengatur waktu belajar dan berlatih.

Tuntutan yang dibebankan pada siswa atlet, dalam hal ini tuntutan akademik dan tuntutan sebagai atlet, membuat mereka harus bisa mengatur dan mengarahkan perilaku mereka untuk dapat memenuhi tuntutan-tuntutan tersebut. Siswa atlet perlu mengatur diri dengan cara merencanakan strategi, mengatur waktu, menetapkan target yang harus dicapai, memotivasi diri dalam menjalankan tuntutan belajar dan berlatih. Siswa atlet juga harus mampu melaksanakan rencana dan strategi yang sudah mereka buat, serta mengontrol perilaku mereka agar mereka dapat mengoptimalkan kemampuan akademis dan olahraga.

Kemampuan-kemampuan tersebut perlu dimiliki untuk mengaktifkan diri pribadinya, atau disebut dengan regulasi diri. Regulasi diri (Zimmerman, 2008) adalah kemampuan untuk mengaktifkan pikiran, perasaan, dan tingkah laku yang telah direncanakan dan sistematis disesuaikan dengan kebutuhan siswa untuk mempengaruhi belajar dan motivasi. Ewing dan Seefeld (dalam Zimmerman, 2008) dalam penelitianya mengenai siswa atlet di Amerika menyebutkan bahwa prestasi 
belajar tinggi membutuhkan lebih dari sekedar bakat dan instruksi yang berkualitas tinggi, tetapi juga pada keyakinan diri, ketekunan, dan kedisiplinan diri. Ketiga hal tersebut menunjukkan adanya dimensi kompetensi yang sifatnya regulasi diri. Berdasarkan uraian di atas peneliti ingin mengetahui bagaimanakah regulasi diri siswa SKO Ragunan?

\section{METODE PENELITIAN}

Populasi dari penelitian ini berjumlah 222 siswa atlet SKO Ragunan Binaan Pemprov DKI. Teknik pengambilan sampel dalam penelitian ini adalah dengan probability sampling (simple random sampling). Penelitian ini termasuk ke dalam jenis penelitian deskriptif kuantitatif yang sifatnya non-eksperimental. Penelitian ini dilakukan di Jakarta, dan instrumen ukur dalam penelitian ini menggunakan kuesioner, yang disebarkan kepada sampel penelitian. Di dalam kuesioner tersebut terdapat satu variabel, yaitu regulasi diri. Di dalam variabel regulasi diri Omrod (2009) aspek-aspek yang terkandung yaitu a) Standar dan tujuan yang ditentukan sendiri, b) Pengaturan emosi, c) Instruksi diri, d) Monitoring diri, e) Evaluasi diri, f) Kontingensi yang ditetapkan sendiri. Analisis data dalam penelitian ini akan menggunakan program statistik, dengan beberapa teknik, yaitu: Uji Kategorisasi Regulasi Diri dan Uji Perbedaan Regulasi Diri berdasarkan Data Penunjang yaitu jenis kelamin, jenjang sekolah, dan cabang olahraga.

\section{HASIL DAN DISKUSI}

Tabel 1-Jumlah Subjek Penelitian

\begin{tabular}{lcrrcr}
\hline & N & Minimum & Maximum & Mean & Std. Deviation \\
\hline Jumlah subjek & 222 & 143,00 & 206,00 & 177,0676 & 11.38388 \\
Valid N (listwise) & 222 & & & & \\
\hline
\end{tabular}

Berdasarkan tabel 1 dapat diketahui bahwa jumlah siswa dalam penelitian ini adalah 222 siswa dan rata-rata nilai regulasi diri 177, 06.

Tabel 2-Cabang Olahraga

\begin{tabular}{|c|c|c|c|}
\hline & & Frequency & Percent \\
\hline \multirow{8}{*}{ 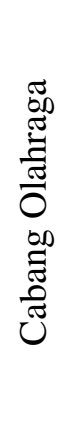 } & Panahan & 12 & 5.4 \\
\hline & Renang & 11 & 5.0 \\
\hline & TInju & 4 & 1.8 \\
\hline & Judo & 8 & 3.6 \\
\hline & Angkat Besi & 12 & 5.4 \\
\hline & Sepak Takraw & 18 & 8.1 \\
\hline & Tenis Meja & 10 & 4.5 \\
\hline & Karate & 11 & 5.0 \\
\hline
\end{tabular}




\begin{tabular}{lrr} 
Atletik & 18 & 8.1 \\
Taekwondo & 13 & 5.9 \\
Pencak Silat & 15 & 6.8 \\
Sepak Bola & 22 & 9.9 \\
Bola Voli & 23 & 10.4 \\
Bola Basket & 22 & 9.9 \\
Gulat & 13 & 5.9 \\
Bulu Tangkis & 10 & 4.5 \\
Total & 222 & 100.0 \\
\hline
\end{tabular}

Berdasakan tabel 2 dapat diketahui bahwa jumlah subjek berdasarkan cabang olahraga paling banyak adalah cabang olahraga bola voli.

Tabel 3-Perbedaan regulasi diri pada laki-laki dan perempuan

\begin{tabular}{llrrrr}
\hline & & & & & \multicolumn{2}{c}{ Std. Error } \\
& Jenis Kelamin & \multicolumn{1}{c}{$\mathrm{N}$} & \multicolumn{1}{c}{ Mean } & Std. Deviation & \multicolumn{1}{c}{ Mean } \\
\hline \multirow{2}{*}{ skortotal } & Laki-laki & 115 & 177.9217 & 11.95543 & 1.11485 \\
& Perempuan & 107 & 176.1495 & 10.71571 & 1.03593 \\
\hline
\end{tabular}

Dari tabel 3 dapat dilihat bahwa jumlah subjek berjenis kelamin laki-laki sebanyak 115 orang sedangkan subjek berjenis kelamin perempuan sebanyak 107 orang. Nilai rata-rata regulasi diri pada subjek laki-laki lebih tinggi dibandingkan regulasi diri pada subjek perempuan $(177,92>176,15)$. Berdasarkan Independent Samples Test dapat diketahui bahwa tidak ada perbedaan yang signifikan antara regulasi diri lakilaki dan perempuan (sig. $=0,115 ; \mathrm{p}>0,05)$.

Tabel 4-Perbandingan regulasi diri siswa SMP dan SMA

\begin{tabular}{llrcrr} 
& & & & & \multicolumn{2}{c}{ Std. Error } \\
& Jenjang Sekolah & N & Mean & Std. Deviation & \multicolumn{1}{c}{ Mean } \\
\hline Skor & SMP & 52 & 177.1346 & 9.65692 & 1.33917 \\
Total & SMA & 170 & 177.0471 & 11.88794 & .91176 \\
\hline
\end{tabular}

Berdasarkan tabel 4 dapat dilihat berdasarkan jenjang sekolah, subjek dengan tingkat pendidikan SMP $(\mathrm{N}=52)$ memiliki regulasi diri yang lebih tinggi dibandingkan subjek dengan tingkat pendidikan SMA $(\mathrm{N}=170)$, walaupun sangat tipis perbedaannya $(177,12>177,04)$. Berdasarkan perhitungan Independent Samples Test regulasi diri siswa SMP dan SMA didapatkan hasil bahwa tidak ada perbedaan yang signifikan antara regulasi diri subjek dengan tingkat pendidikan SMP dan subjek subjek dengan tingkat pendidikan SMA (Sig. $=0,075 ; \mathrm{p}>0,05)$. 
Tabel 5-Perbandingan regulasi diri cabang olahraga tim dan individu

\begin{tabular}{llrrrr}
\hline & & & & & \multicolumn{2}{c}{ Std. Error } \\
& kat_cabor & N & Mean & Std. Deviation & \multicolumn{1}{c}{ Mean } \\
\hline Skor & Individu & 117 & 176.4017 & 11.09525 & 1.02576 \\
Total & Tim & 105 & 177.8095 & 11.70560 & 1.14235 \\
\hline
\end{tabular}

Dari tabel 5 didapatkan hasil bahwa regulasi diri subjek dari cabang olahraga individu lebih rendah dibandingkan regulasi diri pada subjek dari cabang olahraga tim/beregu $(176,40<177,80)$. Pada pengujian regulasi diri antara subjek dari cabang olahraga individu dan tim/beregu, didapatkan bahwa data dalam penelitian ini adalah homogen, sehingga dapat dikatakan tidak terdapat beda varian antara regulasi diri subjek dari cabang olahraga individu dan subjek dari cabang olahraga beregu/tim $(\mathrm{F}=0,345, \mathrm{t}>0,05)$. Selain itu, perhitungan Independent Samples Test menunjukkan bahwa bahwa tidak ada perbedaan yang signifikan antara regulasi diri subjek dari cabang olahraga individu dan subjek dari cabang olahraga tim/beregu $($ sig. $=0,558 ; \mathrm{p}>0,05)$.

Tabel 6-Kategorisasi Regulasi Diri

\begin{tabular}{crrrr}
\hline & Frequency & Percent & $\begin{array}{c}\text { Valid } \\
\text { Percent }\end{array}$ & $\begin{array}{c}\text { Cumulative } \\
\text { Percent }\end{array}$ \\
\hline Valid Sedang & 192 & 86.5 & 86.5 & 86.5 \\
Tinggi & 30 & 13.5 & 13.5 & 100.0 \\
Total & 222 & 100.0 & 100.0 & \\
\hline
\end{tabular}

Berdasarkan tabel 6 dapat diketahui bahwa dari 222 siswa, diperoleh 192 siswa yang memiliki regulasi diri sedang dan 30 siswa yang memiliki regulasi tinggi.

Tabel 7-Kategorisasi Regulasi Diri per Cabang Olahraga

\begin{tabular}{lllrr}
\hline cabor & kat_regulasidiri & Mean & N & Std. Deviation \\
\hline Panahan & Sedang & 170.2857 & 7 & 5.99206 \\
& Tinggi & 206.0000 & 5 & .00000 \\
& Total & 185.1667 & 12 & 18.91528 \\
Renang & Sedang & 175.8182 & 11 & 5.68890 \\
\multirow{4}{*}{ Tinju } & Total & 175.8182 & 11 & 5.68890 \\
& Sedang & 183.0000 & 1 &. \\
\multirow{3}{*}{ Judo } & Tinggi & 193.0000 & 3 & 3.60555 \\
& Total & 190.5000 & 4 & 5.80230 \\
& Sedang & 181.0000 & 7 & 3.91578 \\
Angkat Besi & Tinggi & 202.0000 & 1 & \\
& Total & 183.6250 & 8 & 8.26244 \\
Sepak Takraw & Sedang & 171.4167 & 12 & 6.65321 \\
& Total & 171.4167 & 12 & 6.65321 \\
& Sedang & 177.8667 & 15 & 9.47830
\end{tabular}




\begin{tabular}{|c|c|c|c|c|}
\hline & Tinggi & 194.6667 & 3 & 8.14453 \\
\hline & Total & 180.6667 & 18 & $11.1037 \mathrm{C}$ \\
\hline \multirow[t]{3}{*}{ Tenis Meja } & Sedang & 180.0000 & 9 & 4.15331 \\
\hline & Tinggi & 195.0000 & 1 & \\
\hline & Total & 181.5000 & 10 & 6.15088 \\
\hline \multirow[t]{2}{*}{ Karate } & Sedang & 177.4545 & 11 & 7.75066 \\
\hline & Total & 177.4545 & 11 & 7.75066 \\
\hline \multirow[t]{3}{*}{ Atletik } & Sedang & 174.0625 & 16 & 7.54072 \\
\hline & Tinggi & 195.5000 & 2 & 7.77817 \\
\hline & Total & 176.4444 & 18 & 10.08915 \\
\hline \multirow[t]{3}{*}{ Taekwondo } & Sedang & 172.8333 & 12 & 9.59008 \\
\hline & Tinggi & 200.0000 & 1 & \\
\hline & Total & 174.9231 & 13 & 11.87758 \\
\hline \multirow[t]{2}{*}{ Pencak Silat } & Sedang & 174.0667 & 15 & 8.11055 \\
\hline & Total & 174.0667 & 15 & 8.11055 \\
\hline \multirow[t]{3}{*}{ Sepak Bola } & Sedang & 173.6667 & 15 & 9.86094 \\
\hline & Tinggi & 192.4286 & 7 & 3.73529 \\
\hline & Total & 179.6364 & 22 & 12.19893 \\
\hline \multirow[t]{3}{*}{ Bola Voli } & Sedang & 172.4545 & 22 & 9.69402 \\
\hline & Tinggi & 193.0000 & 1 & \\
\hline & Total & 173.3478 & 23 & 10.39497 \\
\hline \multirow[t]{3}{*}{ Bola Basket } & Sedang & 170.8500 & 20 & 10.83986 \\
\hline & Tinggi & 196.5000 & 2 & .70711 \\
\hline & Total & 173.1818 & 22 & 12.77884 \\
\hline \multirow[t]{2}{*}{ Gulat } & Sedang & 167.8462 & 13 & 6.45299 \\
\hline & Total & 167.8462 & 13 & 6.45299 \\
\hline \multirow[t]{3}{*}{ Bulu Tangkis } & Sedang & 178.1667 & 6 & 5.81091 \\
\hline & Tinggi & 196.2500 & 4 & 4.71699 \\
\hline & Total & 185.4000 & 10 & 10.64790 \\
\hline \multirow[t]{3}{*}{ Total } & Sedang & 174.0104 & 192 & 8.65813 \\
\hline & Tinggi & 196.6333 & 30 & 5.99703 \\
\hline & Total & 177.0676 & 222 & 11.38388 \\
\hline
\end{tabular}

Berdasarkan tabel 7 dapat diketahui bahwa cabang olahraga panahan lebih banyak yang memiliki regulasi sedang 7 subjek dibandingkan yang tinggi 5 subjek. Cabang olahraga renang, semua subjek yaitu 11 memiliki regulasi sedang. Cabang olahraga tinju lebih banyak yang memiliki regulasi diri tinggi sebanyak 3 subjek dibandingkan yang sedang yaitu 1 subjek. Cabang olahraga judo lebih banyak yang memiliki regulasi sedang sebanyak 7 subjek, dibandingkan yang tinggi yaitu 1 subjek. Cabang olahraga angkat besi semua subjek yaitu 12 memiliki regulasi sedang. Cabang olahraga sepak takraw lebih banyak yang memiliki regulasi sedang sebanyak 15 subjek, dibandingkan yang tinggi sebanyak 3 subjek. Cabang olahraga tenis meja lebih banyak yang memiliki regulasi sedang yaitu sebanyak 9 subjek 
dibandingkan yang tinggi sebanyak 1 subjek. Cabang olahraga karate semua subjek memiliki regulasi sedang sebanyak 11 subjek. Cabang olahraga athletik lebih banyak yang memiliki regulasi sedang sebanyak 16 subjek dibandingkan yang tinggi sebanyak 2 subjek. Cabang olahraga taekwondo lebih banyak yang memiliki regulasi sedang sebanyak 12 subjek dibandingkan yang tinggi sebanyak 1 subjek. Cabang olahraga pencak silat dan sepak bola semua subjek memiliki regulasi diri sedang sebanyak 15 subjek. Cabang olahraga bola voli lebih banyak yang memiliki regulasi sedang sebanyak 22 subjek, dibandingkan yang tinggi sebanyak 1 subjek. Cabang olahraga bola basket lebih banyak yang memiliki regulasi sedang sebanyak 20 subjek, dibandingkan yang tinggi sebanyak 2 subjek. Cabang olahraga gulat semua subjek sebanyak 13 memiliki regulasi sedang. Cabang olahraga bulu tangkis lebih banyak yang memiliki regulasi sedang sebanyak 6 subjek dibandingkan yang tinggi sebanyak 4 subjek.

\section{Diskusi}

Berdasarkan hasil penelitian pada Siswa Sekolah Khusus Olahraga Ragunan Binaan Pemerintah Provinsi DKI Jakarta, dapat diketahui bahwa dari 222 subjek yang memiliki regulasi diri tinggi sebanyak 30 subjek $(13,5 \%)$ dan yang memiliki regulasi sedang sebanyak 192 subjek (86,5\%). Hal ini berarti bahwa siswa di Sekolah Khusus Olahraga Ragunan Binaan Pemerintah Provinsi DKI Jakarta yang memiliki regulasi tinggi mampu merencanakan strategi, mengatur waktu antara sekolah dan olahraga, mampu menetapkan target yang harus dicapai baik dalam akademik maupun olahraga, mampu memotivasi diri dalam menjalankan tuntutan belajar dan berlatih, mampu melaksanakan rencana dan strategi yang sudah mereka buat, serta mengontrol perilaku mereka agar mereka dapat mengoptimalkan kemampuan akademis dan olahraga.

Berdasarkan tabel 3 dapat diketahui bahwa laki-laki memiliki regulasi lebih baik dibandingkan perempuan. Menurut Jenny (2001) yang menyatakan bahwa di Israel dan Singapura laki-laki lebih baik regulasi diri belajarnya dibanding perempuan. Sedangkan berdasarkan hasil Uji Independent Sample Test dapat diketahui bahwa tidak ada perbedaan yang signifikan antara regulasi diri laki-laki dan perempuan (sig. $=0,115 ; p>0,05$ ). Hal ini sesuai dengan Smith (dalam Waluya, 2007) bahwa perbedaan jenis kelamin merupakan salah satu kategori yang diperolah manusia sejak lahir. Jenis kelamin juga merupakan salah satu unsur pembeda dalam diferensiasi sosial. Secara hakiki, perbedaan laki-laki dan perempuan bersifat horizontal atau tidak menunjukkan perbedaan derajat yang tinggi atau rendah, sebab perbedaan tersebut hanya menyangkut bentuk dan sifat dasar.

Berdasarkan tabel 4 dapat diketahui bahwa siswa SMA (N=170) lebih memiliki regulasi diri yang rendah dibandingkan siswa SMP $(\mathrm{N}=52)$. Hal ini diduga 
karena siswa SMP masih memiliki keinginan belajar yang lebih dan lebih mudah diatur oleh pelatih, sehingga lebih mampu untuk melakukan regulasi diri. Hasil ini berbanding terbalik dengan penelitian yang menyatakan bahwa perkembangan kemampuan regulasi akan meningkat sesuai dengan meningkatnya kapasitas kognitif saat dewasa (misalnya kemampuan berpikir abstrak dan kemampuan perencanaan). Perkembangan akan semakin matang ketika beranjak dewasa. Menurut Radovan (2010) individu yang lebih tua lebih terampil dalam menggunakan kemampuan belajar berdasar regulasi diri dibanding mereka yang lebih muda. Hal ini terkait dengan perkembangan kemampuan berpikir formal dan pengalaman sebelumnya (Moss \& Azevedo, dalam Radovan, 2010). Namun berdasarkan hasil Independent Samples Test diketahui bahwa tidak ada perbedaan yang signifikan antara regulasi diri dengan tingkat pendidikan (Sig. $=0,075 ; \mathrm{p}$ $>0,05)$.

Berdasarkan tabel 5 dapat diketahui bahwa cabang olahraga tim memiliki regulasi yang lebih tinggi $(\mathrm{N}=105)$ dibandingkan yang individu $(\mathrm{N}=117)$. Hal ini diduga bahwa dengan adanya tim, akan membuat anggota dalam tim mengikuti dan menyontoh regulasi diri dari anggota yang memiliki regulasi yang tinggi. Namun berdasarkan perhitungan Independent Samples Test menunjukkan bahwa bahwa tidak ada perbedaan yang signifikan antara regulasi diri subjek dari cabang olahraga individu dan subjek dari cabang olahraga tim/beregu (sig.=0,558; $\mathrm{p}>0,05$ ).

\section{KESIMPULAN}

Berdasarkan hasil penelitian dapat disimpulkan bahwa siswa Sekolah Khusus Olahraga Ragunan Binaan Pemerintah Provinsi DKI Jakarta diketahui bahwa dari 222 subjek yang memiliki regulasi diri sedang lebih banyak dari pada siswa yang memiliki regulasi tinggi. Selain itu siswa laki-laki lebih memiliki regulasi yang baik dibandingkan siswa perempuan. Dan siswa dengan cabang olahraga beregu atau tim memiliki regulasi yang tinggi disbanding siswa dari cabang olahraga individu.

\section{DAFTAR PUSTAKA}

Alwi, H. (2005). Kamus Besar Bahasa Indonesia. Jakarta: Departemen Pendidikan Nasional Balai Pustaka.

Azwar, S. (1996). Realibilitas dan Validitas, Interpretasi dan Komputasi. Yogyakarta: Liberty.

Waluya, B. (2007). Sosiologi Menyelami Fenomena Sosial di Masyarakat. Bandung: PT. Setia Purna. 
Bandura, A. (1989). Self-Efficacy Mechanism in Psysiological Activation and Health-Promoting Behavior. In J. Madden, S. Matthysse, \& J. Barchas (Eds.). Adaptation, learning, and affect. Ner York: Raven.

Boekaerts, M. (2000). Handbook of Self-Regulation. San Diego, California: Academic Press.

Hutabarat, J. (1995). Penerapan Rekayasa Nilai Untuk Mendapatkan Nilai Tambah Pada Perusahaan Sandal Wanita, diakses dari http://eprints.upnjatim.ac.id/124/1/210107-47-54.pdf

Jenny, K. (2001). Self regulated strategies in achievement settings cullture and gender differences. Universitas of Haifa. Journal of Cross Cultural Phychology, 32(4), 491-503.

Kusumawati, E. D. (2017). Pengaruh Adversity Quotient terhdp Regulasi Diri Siswa KElas Khusus Olahraga (KKO) SMP Negeri 13 Yogyakarta. Jurnal Pendidikan Masrasah, 2(1), 2527-4287.

Omrod, J. E. (2009). Psikologi Pendidikan: Membantu Siswa Tumbuh dan Berkembang, terj. Amitya Kumara. Jakarta: Erlangga.

Pintrich, P.R., \& De Groot, E.V. (1990). Motivational and Self-Regulated Learning Componens of Classroom Academic Performance. Journal of Educational Psychology, 82(1), 33-40.

Purwanto. (2010). Evaluasi Hasil belajar. Yogyakarta: Pustaka Pelajar

Radovan, M. (2010). The influence of self regulated learning and age on success in studying. Journal of Contemporary Educational Studies,5, 102-124

Sukmadinata, N. S. (2009). Metode Penelitian Pendidikan. Bandung: Rosdakarya.

Suryabrata, S. (2011). Psikologi Pendidikan. Jakarta: PT. Raja Grafindo Persada

Zimmerman, B. J. (2000). Self-Efficacy: An Essential Motive to Learn. Contemporary Educational Psychology, 25, 82-91

Zimmerman, B. J. (2008). Investigating Self-Regulation and Motivation: Historical Background, Methodological Developments, and Future Prospects. American Eductional Research Journal, 45(1), 166-183. 